\title{
Spontaneous Retroperitoneal Hematoma Originating at Lumbar Arteries in Context of Cirrhosis
}

Jennifer A. Best, MD
Mark W. Smith, MD
Division of General Internal Medicine, University of Washington, Seattle, Washington.

Journal of Hospital Medicine 2010;5:E4-E5. (C) 2010 Society of Hospital Medicine.

KEYWORDS: acute abdominal emergencies, liver failure, cirrhosis.

A 56-year-old male presented to the emergency department with a 2-week history of increasing abdominal girth, nausea, vomiting, and lower extremity edema. His girlfriend had also noted a yellow tinge to his skin and eyes. His past medical history was significant for bipolar disorder, alcoholrelated seizures, and pneumonia. He had no allergies and denied medications prior to admission. Family history was negative for liver disease and social history was notable for ongoing tobacco use and alcohol dependence. He was afebrile with stable vital signs. Physical examination demonstrated an alert gentleman whose answers to questions required occasional factual correction by his partner. His abdomen was distended and nontender with prominent vasculature and shifting dullness. Lower extremity edema was symmetric and bilateral, rated as $2+$. Scattered spider angiomata and a fine bilateral hand tremor without asterixis were also noted. Initial laboratory data demonstrated a white blood cell count of $13,900 / \mu \mathrm{L}$, hematocrit $37 \%$, and platelet count $176,000 / \mu \mathrm{L}$. His sodium was $130 \mathrm{mg} / \mathrm{dL}$, blood urea nitrogen (BUN) $1 \mathrm{mg} / \mathrm{dL}$, and creatinine $0.7 \mathrm{mg} /$ $\mathrm{dL}$. International normalized ratio (INR) was 1.8, aspartate aminotransferase (AST) was $117 \mathrm{U} / \mathrm{L}$, alanine aminotransferase (ALT) $33 \mathrm{U} / \mathrm{L}$, alkaline phosphatase $191 \mathrm{U} / \mathrm{L}$, total bilirubin $9.2 \mathrm{mg} / \mathrm{dL}$, total protein $7.0 \mathrm{~g} / \mathrm{dL}$, and albumin $1.9 \mathrm{~g} / \mathrm{dL}$. Abdominal ultrasound revealed a diffusely hyperechoic liver with a large amount of ascites.

The patient was admitted with the diagnoses of presumed alcoholic hepatitis and end-stage liver disease. Model for End-Stage Liver Disease (MELD) score was 21 and discriminant function 16.8. Paracentesis demonstrated a serum-ascites albumin gradient of $>1.1$ and no evidence of spontaneous bacterial peritonitis. Diuresis was initiated. He was placed on unfractionated heparin at a dose of 5000 units every 8 hours for deep venous thrombosis (DVT) prophylaxis. By hospital day 3, the patient's laboratory values had improved, yet his stay was prolonged by alcohol withdrawal requiring benzodiazepines, altered mental status presumed secondary to hepatic encephalopathy, acute renal failure, aspiration pneumonia, and persistent unexplained leukocytosis. He required medical restraints during this time given confusion and propensity to ambulate without assistance, yet sustained no falls or other known trauma in care delivered during this time.
Between days 14 and 17, the patient's hematocrit fell from $36 \%$ to $30 \%$; vital signs remained stable. He underwent an uncomplicated, ultrasound-guided therapeutic paracentesis, which yielded 1.4 L of straw-colored fluid on the afternoon of day 17; the procedure was attempted only on the right side. On the morning of day 18, the patient's blood pressure dropped to $78 / 55 \mathrm{mmHg}$ with a pulse of 123 beats per minute; he became pale and unresponsive. Physical examination was notable for somnolence and a tender, warm left flank mass, contralateral to his paracentesis site. No flank or periumbilical ecchymoses were identified. Complete blood count demonstrated a white blood count (WBC) of $22,970 / \mu \mathrm{L}$, hematocrit $16 \%$, and platelet count $104,000 / \mu \mathrm{L}$. INR was 2.0, unchanged from the last check on day 10. Partial thromboplastin time was 41 seconds and fibrinogen was 293 mg/dL (normal 150-400 mg/dL). Peripheral blood smear was negative for red cell fragments. Blood chemistries revealed a sodium of $134 \mathrm{mg} / \mathrm{dL}$, bicarbonate $20 \mathrm{mEq} / \mathrm{L}$, anion gap 7, BUN $24 \mathrm{mg} / \mathrm{dL}$, and creatinine $1.6 \mathrm{mg} / \mathrm{dL}$ (up from $1.0 \mathrm{mg} / \mathrm{dL}$ the previous day). His venous lactate level was $4.6 \mathrm{mmol} / \mathrm{L}$ and arterial blood gas sampling on room air demonstrated a $\mathrm{pH}$ of 7.35, partial pressure of carbon dioxide $\left(\mathrm{pCO}_{2}\right) 29 \mathrm{mmHg}$, partial pressure of oxygen $\left(\mathrm{pCO}_{2}\right)$ $54 \mathrm{mmHg}$, and bicarbonate $15 \mathrm{mEq} / \mathrm{L}$. A femoral introducer was placed for volume resuscitation and the patient was urgently transfused with packed red blood cells (PRBCs) and fresh-frozen plasma (FFP) to correct his coagulopathy. Computed tomography of the abdomen revealed a large left retroperitoneal hematoma measuring $15 \times 15 \times 22 \mathrm{~cm}^{3}$ (Figure 1). Despite transfusion, his hematocrit continued to fall. Urgent angiography was performed, upon which he was found to have active bleeding from the left L3-L5 lumbar arteries. These were successfully embolized. He required PRBCs and FFP transfusion only once following this procedure. Given a transient decrease in his urine output, his bladder pressures were followed closely for evidence of abdominal compartment syndrome, which did not develop. He was transferred from the intensive care unit (ICU) to the floor on day 20, where his physical exam and hematocrit remained stable and his delirium slowly cleared. He was ultimately discharged to a skilled nursing facility on day 33. 


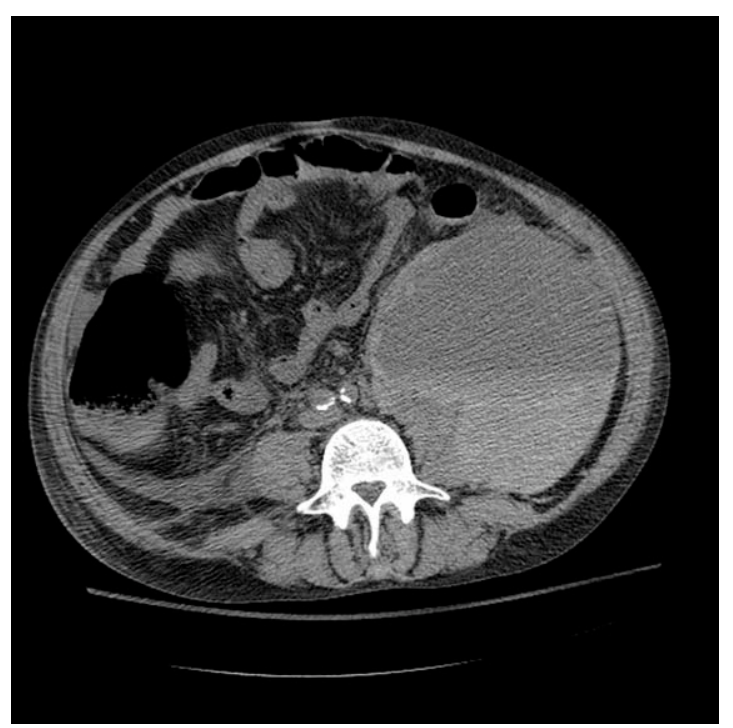

FIGURE 1. Noncontrast computed tomography (CT) scan of the abdomen and pelvis demonstrating a $15 \times 15 \times 22 \mathrm{~cm}^{3}$ left retroperitoneal mass anterior to the left psoas with dependent hyperdensity consistent with a hematocrit-fluid level.

\section{Discussion}

Spontaneous retroperitoneal hematoma is a well-recognized entity that may present with the classic triad of abdominal or groin pain, palpable abdominal or flank mass, and shock or lower extremity motor or sensory changes due to femoral nerve compression. ${ }^{1}$ Although classically described as skin findings associated with retroperitoneal hemorrhage, Cullen and Grey-Turner signs are relatively late findings that may not develop in all patients.

Retroperitoneal hemorrhage is well-recognized as a result of iatrogenic anticoagulation, ${ }^{1}$ but has been reported less commonly as a result of coagulopathy related to cirrhosis. Di Bisceglie and Richart ${ }^{2}$ describe 2 patients with MELD scores of 29 and 25, respectively, who developed spontaneous retroperitoneal and rectus muscle hemorrhage. Both had evidence of associated disseminated intravascular coagulation (DIC) and died. Even less common is spontaneous lumbar artery rupture, occurring rarely in the absence of trauma or instrumentation. One reported bleed developed in the context of systemic anticoagulation for a mechanical valve. ${ }^{3}$ Halak et al. ${ }^{4}$ relate a case in which the only known risk factor was chronic renal disease. Hama et al. ${ }^{5}$ describe a patient with a history of alcoholic liver cirrhosis and INR of 2.3 whose lumbar artery rupture was successfully managed with transcatheter arterial embolization.

It is difficult to ascertain the effect of prophylactic anticoagulation in development of this particular hemorrhage. Retroperitoneal bleeding is a very rare complication of phar- macologic prophylaxis for DVT reported with both low-molecular weight and unfractionated heparins. ${ }^{6}$ There may be additive risk of prophylaxis in a cirrhotic patient with baseline elevated INR and thrombocytopenia, particularly in the context of renal failure.

Options in the management of spontaneous retroperitoneal hematoma include transarterial embolization, percutaneous decompression, and open surgery. Nonoperative management of these bleeds when possible may be preferable in cirrhotic patients, as their baseline liver disease renders them higher-risk candidates for surgery. There are no randomized trials comparing these approaches. ${ }^{1}$

In summary, we report the case of a 56-year-old man with end-stage liver disease and associated coagulopathy without evidence of DIC who survived to discharge with intravascular management of a spontaneous retroperitoneal hemorrhage from the lumbar arteries. To our knowledge, this is the second reported case of spontaneous retroperitoneal hemorrhage in a cirrhotic in which the lumbar arteries were implicated and the first in which multiple arteries were found to be bleeding simultaneously. Any hospitalized patient who develops abdominal pain, flank pain, or hemodynamic instability in the context of coagulopathy, regardless of cause, warrants evaluation for retroperitoneal bleed. Appropriate early management includes immediate resuscitation, intensive monitoring, urgent imaging, and surgical and interventional radiology consultation in order to prevent a fatal outcome.

\section{Address for correspondence and reprint requests:}

Jennifer A. Best, MD, University of Washington, Division of General Internal Medicine, Box 359780, 325 Ninth Avenue, Seattle, WA 98104; Telephone: 206-744-3249; Fax: 206-744-6063; E-mail: jabest@u.washington.edu Received 22 September 2008; revision received 10 January 2009; accepted 16 January 2009.

\section{References}

1. Chan YC, Morales JP, Reidy JF, Taylor PR. Management of spontaneous and iatrogenic retroperitoneal haemorrhage: conservative management, endovascular intervention or open surgery? Int J Clin Pract. 2007;62: 1604-1613.

2. Di Bisceglie AM, Richart JM. Spontaneous retroperitoneal and rectus muscle hemorrhage as a potentially lethal complication of cirrhosis. Liver Int. 2006;26:1291-1293.

3. Schuster F, Stosslein F, Steinbach F. Spontaneous rupture of a lumbar artery. A rare etiology of retroperitoneal hematoma. Urologe A. 2003;42: 840-844.

4. Halak M, Kligman M, Loberman Z, Eyal E, Karmeli R. Spontaneous ruptured lumbar artery in a chronic renal failure patient. Eur J Vasc Endovasc Surg. 2001;21:569-571.

5. Hama Y, Iwasaki Y, Kawaguchi A. Spontaneous rupture of the lumbar artery. Intern Med. 2004;43:759.

6. Leonardi MJ, McGory ML, Ko CY. The rate of bleeding complications after pharmacologic deep venous thrombosis prophylaxis. Arch Surg. 2006;141: 790-799. 